\title{
INVENTARIO DE LOS CUADROS Y LIBROS DE RUY GOMEZ DE SILVA, III DUQUE DE PASTRANA $(1626)$
}

Ruy Gómez de Silva de Mendoza y de la Cerda, III duque de Pastrana, nació en Valencia a principios de octubre de 1585 . Hijo mayor de Rodrigo de Silva y Mendoza (II duque) y Ana de Portugal y Borja, y nieto de Ruy Gómez de Silva y Ana de Mendoza y de la Cerda, principes de Eboli, provenía de una de las familias políticamente más fuertes del reinado de Felipe II. De hecho, se llamaba siempre Ruy Gómez de Silva, en memoria de su célebre abuelo, primer consejero del rey hasta su muerte en 1573 .

Su padre era militar de profesión : había servido en la conquista de Portugal (1580) y luego fue nombrado Capitán de la Caballería Ligera. Con este cargo pasó a los Países Bajos, donde se juntó con el duque de Parma. En 1594 el joven Ruy Gómez (aún no alcanzaba los nueve años) acompañó a su padre desde Milán a Flandes y estuvo alli cuando el II duque murió a consecuencia de sus heridas en Luxemburgo en 1596. Temiendo el estilo de vida que su hijo pudiera seguir en la corte madrileña (¿tendría en cuenta la mala vida que había llevado él mismo de joven?) ${ }^{1}$, Rodrigo de Silva había dispuesto que se quedase en Flandes "adonde le tenia yà escogido por

1 Según lo cuenta G. Marañón, Rodrigo de Silva, II duque de Pastrana, fue nada menos que un delincuente juvenil, que en otros tiempos habría acabado en un reformatorio de menores: "Con el Marqués de la Fábara y Don Alonso de Leiva, famosos capitanes de los de entonces, iguales en el heroísmo y en la insensatez, formó un grupo de caballeretes juerguistas que sembraba por donde iban el terror" (Antonio Péres [El hombre, el drama, la época], Madrid, 1948, I, págs. 184-85). 
Maestro al gran Iusto Lipsio, Fenix de nuestros tiempos" 2. Sin embargo, a pesar de las loables intenciones del padre, en febrero de 1596 Ruy Gómez fue llevado a España por el duque de Feria para que lo cuidara su madre, "Heroica Matrona, y tal que en todo genero de virtudes, se ha puesto en tan alto estado, que dexa atras a muchas, de las mas espirituales" " .

Con solo once años, Ruy Gómez de Silva era ahora III duque de Pastrana y grande de España. En 1598 acompañó al nuevo rey Felipe III (habiendo sido años atrás menino del joven príncipe) en la primera entrada pública que hizo en Madrid; el mismo año se concertaron capitulaciones matrimoniales entre él y su prima hermana Leonor de Guzmán (hija del duque de Medina Sidonia y Ana de Silva y Mendoza, tía de Ruy Gómez).

Al alcanzar la mayoría de edad, en 1605, tomó control de su casa y estados, inicio de un proceso en que paulatinamente fue adquiriendo estados y títulos (como los de Almenara y Galve), al morir sin sucesión miembros de su extensa familia. Así, en 1606, con la muerte de su tía Ana de Silva, condesa de Cifuentes, "recayò en èl la primogenitura de la Casa de Silva, y el Titulo, Estados, y mayorazgos de los Condes de Cifuentes, como visnieto mayor de Doña Catalina de Silva, Princesa de Melito" ". Sin embargo, la adquisición de títulos y estados por parte cle Ruy Gómez no fue un proceso totalmente desembarazado de problemas: en cuanto a los estados de Cifuentes, se levantaron contra él, entre muchos, su hermano Diego y su tío el conde de Salinas. En consecuencia, empezó un pleito que dio abasto a abogados durante muchos decenios, aunque Ruy Gómez siempre añadía el título de conde de Cifuentes a los otros que poseía. Puesto que con el título de conde de Cifuentes iba el de Alférez Mayor de Castilla, se puede entender mejor la lucha enconada por poseerlo ${ }^{5}$. Entre otros pleitos, Ruy Gómez había heredado de su padre uno con el conde de Salinas sobre los estados del ducado de Francavila (ducado que ambos hermanos disputaban), y con el mismo Salinas tuvo más tarde otro pleito sobre las villas de La Chamusca y Ulme, ya que Salinas alegaba la incompatibilidad de que su sobrino fuese dueño de ambas Pastrana y La Chamusca. Como observa lacónicamente Salazar y Castro: "pero aunque por ambas partes se hizieron diferentes alegatos, tuvieron fin las vidas de estos Señores, antes que viessen

2 L. Salazar y Castro, Historia genealógica de la Casa de Silva, donde se refieren las acciones más señaladas de sus señores, las fundaciones de sus mayorazgos y la calidad de sus alianças matrimoniales, Madrid, 1685, II, pág. 565.

3 P. de Salazar y de Mendoza, Cronica de el gran Cardenal de España, don Pedro Gonçales de Mendoça, Toledo, 1625, pág. 463.

4 Salazar y Castro, Casa de Silva, pág. 566.

5 Al fin, Pastrana perdió este pleito y el título fue adjudicado a Pedro de Silva Girón, aunque Pastrana consiguió retener el mayorazgo y algunas de las villas del condado de Cifuentes. 
el de sus pleytos, y los continuaron sus hijos" ". En lo que a pleitos se refiere, esta familia, desde luego, no andaría lejos en el siglo xvir de ostentar el récord mundial.

En 1612 ocurrió un hecho de gran importancia para España y también para el duque de Pastrana, al tratarse las capitulaciones matrimoniales del príncipe Felipe con Isabel de Borbón y de Luis XIII con Ana de Austria. El duque de Humena representó los intereses de Francia en España, mientras que Pastrana fue escogido por Felipe III para el mismo cargo en Francia, "con el titulo de su Embaxador Extraordinario, fiando de su juyzio, y de la grandeza de su espiritu, y de su casa, que sabria llenar enteramente la autoridad de aquella funcion" ". Salió de Madrid el 5 de julio en compañía de sus hermanos Francisco y Diego y su tío el conde de Galve ${ }^{8}$. Llegaron a París el 13 de agosto, donde Pastrana dejó "perpetua memoria de su vizarria, y afabilidad, dotes muy propios de su persona" ". Felipe III quedó tan contento de su actuación que, cuando Pastrana volvió a Madrid, le nombró Gentilhombre de su Cámara y Cazador Mayor de la Volatería, con una buena Encomienda de la Orden de Santiago. Cuando el 9 de noviembre de 1615 se llegó a celebrar el doble matrimonio al lado del río $\mathrm{Bi}$ dasoa, Pastrana tomó otra vez parte principal en el acontecimiento.

Según Juan Bautista Labaña en su narración del viaje y visita de Felipe III a Portugal en 1619, Ruy Gómez de Silva acompañó el séquito real. Si fuera así, se habría reunido a la fuerza en Lisboa con su tío Diego de Silva y Mendoza, conde de Salinas, marqués de Alenquer y Virrey de Portugal. Teniendo en cuenta el gran número de pleitos pendientes entre los dos, se puede imaginar el tipo de reunión que habría sido ${ }^{10}$. Aunque Pastrana fue noble muy asociado con el gobierno de Felipe III y el duque de Lerma, no sufrió revés como muchos otros con el cambio de régimen ocurrido en 1621. Consiguió retener sus puestos de Gentilhombre de la Cámara y Cazador Mayor, y pronto fue llamado por el nuevo rey para un cargo de suma importancia.

A principios de 1623 Felipe IV le nombró Embajador Extraordinario ante la Santa Sede en Roma ${ }^{11}$. Desde hacía unos meses la situación en la

\footnotetext{
- Salazar y Castro, Casa de Silva, pág. 548.

7 Salazar y Castro, Casa de Silva, pág. 569.

8 Francisco y Diego de Silva fundaron la "Academia Selvaje" en Madrid, academia de literatos que tuvo vida entre 1611 y 1614.

- Salazar y Castro, Casa de Silva, pág. 573.

10 En 1620 Salinas pidió permiso al rey para volver a Madrid para proseguir el pleito, temiendo que su sobrino aprovechase su ausencia para derrotarlo en los tribunales. Sobre esto, véase T. J. DADson, "Nuevos datos para la biografía de Don Diego de Silva y Mendoza, Conde de Salinas", Criticón, 31 (1985), pág. 68, nota 14.

11 Cf. L. Salazar y Castro, "Y como para negocios de suma consideracion fuesse preciso, que passasse à Roma vn Personage de representacion grande, le nombrò
} 
Valtellina se volvía muy problemática y espinosa, con España y Francia a punto de entrar en guerra para apoderarse cada una de este paso tan esencial para el Camino Español que unía los Países Bajos con Italia. Al papa Gregorio XV le había tocado el nada deseable papel de mediar en el asunto, y Pastrana fue enviado a Roma para presentar los argumentos españoles. Salió de Madrid el 3 de marzo de 1623, "y aunque a la ligera y en secreto, lleuò mas de cien personas con los criados y allegados a su persona $\mathrm{y}$ benignidad" 12. Embarcó en Barcelona el 23 de abril, llegando a Roma en mayo. Durante el viaje, la flota española avistó una escuadra turca y logró capturar unos cuantos navíos y a más de 150 turcos. La noticia de este éxito le precedió a Pastrana a Roma, y cuando llegó, fue recibido con grandes honores. Se alojó en una quinta particular del papa en las afueras de la ciudad y fue tratado con suma afabilidad. Aunque su misión fue interrumpida por la muerte de Gregorio XV, ocurrida el 8 de julio de 1623, Pastrana aprovechó la ocasión para trabajar incesantemente por promover a un candidato ameno a los intereses españoles en el norte de Italia. Tuvo la suerte de conocer bastante bien a Maffeo Barberini antes de que éste llegase a ser papa (con el nombre de Urbano VIII); como dijo un observador contemporáneo: "era grandissima la aficion y amistad que le tenia" 13. En seguida, el nuevo papa escribió a Fray Pedro González de Mendoza, arzobispo de Zaragoza y tío de Pastrana, alabándole mucho, y se cuenta lo siguiente de su tratamiento para con el Embajador español: "Y ultimamente son tantas las mercedes y fauores $q[u e]$ le haze su Santidad al Duque, que parece $[n]$ increibles, pues de su mesma mesa, quando come, ò cena, dize : lleuen este plato al Duque de Pastrana, Embaxador de España; sin otros infinitos regalos y agasajos que escriuen de Roma le haze su Santidad" 14.

A raíz de los éxitos de Pastrana en Roma, Felipe IV decidió retenerlo allí, nombrándole Embajador ordinario (es decir, permanente) en lugar del duque de Albuquerque ${ }^{15}$. La embajada de Roma era de las más importantes de que disponía España, y tal subida prueba la estima en que fue tenido Ruy Gómez de Silva. Como escribió Pedro de Salazar y de Mendoza en

su Magestad para esta jornada en los primeros dias del año mil seiscientos y veinte y tres" (Casa de Silva, pág. 575).

12 BNM MS 2355, Sucesos del año 1624, fol. 498r.

18 BNM MS 2355, fol. 498v.

14 BNM MS 2355, fol. $498^{v}$.

16 Una carta del papa Urbano VIII a Felipe IV con fecha de enero de 1624 subraya el éxito de la embajada de Pastrana: "assi nos alegramos mas de lo que podremos significar, luego que V. Mag[esta]d le publico por su embajador ordinario cerca de n[uest]ra persona con mucho gusto le oimos proponer no con menor eleganzia que fidelidad lo que a V. Mag[esta]d toca y en esta corte y concurso de todo el orbe a conseruado la dignidad de su offizio de manera que la voz comun le juzga merezedor de n[uest]ro fauor y amparo" (BNM MS 2354, Sucesos del año 1623, fol. 233r). 
1625 (cuando Pastrana todavía ocupaba el puesto): "yo tengo por cierto, que la Embajada de Roma, es la cosa de mas substancia, y confiança, que proueen los Reyes. La que ha menester mas hombre, por la variedad de cosas graues, que han de pasar por sus manos. Los Virreyes son ayudados de Consegeros, y ministros. El Embajador de Roma lo ha de ser solamente de su entendimiento, y cordura: y esto ha de gouernalle. Si se hierra, en nada pueden ser mayores los errores, que en este ministerio" ${ }^{10}$.

En mayo de 1624 Pastrana recibió el puesto de Consejero de Estado por sus muchos méritos, pero ya deseaba volver a España. Hay que recordar que había sido enviado en primer lugar como Embajador Extraordinario, puesto de duración presumiblemente corta. Hacia diciembre de 1624 el duque escribió al rey pidiendo permiso para regresar, permiso que le fue concedido con tal de que esperase hasta que llegara el nuevo embajador, el conde de Oñate. Desafortunadamente para Pastrana, la invasión francesa de los pasos de la Valtellina a finales de 1624 y la incierta situación que reinaba en el norte de Italia durante 1625, hicieron mella en los cálculos del gobierno español, y Pastrana no pudo salir de Roma hasta octubre de 1626. Cuando llegó a Madrid en noviembre, estaba "tan molestado de rigurosos achaques, que ellos le quitaron la vida el dia veinte y tres de Diziembre del mismo año" ${ }^{17}$. Tal como su padre (que murió a la edad de treinta y cuatro años), Ruy Gómez de Silva murió joven y en pleno desarrollo de sus facultades. No sobraban nobles inteligentes y con experiencia política en la corte de Felipe IV como para que no se notase su falta. Su viuda, Leonor de Guzmán ("Aue Phenix de España", como la llama Pedro de Salazar y de Mendoza) ${ }^{18}$, se quedó encargada de sus estados $y$, es de suponer, de sus interminables y múltiples pleitos.

Pocos días después de la muerte de Pastrana, se hizo inventario "de los vienes que quedaron por la fin y muerte del ex. ${ }^{\text {mo }}$ señor Ruy Gomez de silva Principe de melito y Duque de Pastrana" ${ }^{19}$. Entre los bienes inventariados, hay dos apartados que nos interesan aquí: los cuadros (fols. $660^{\text {r }}$ $662^{v}$ ) y los libros (fols. $680^{v}-683^{v}$ ). Sobre los libros hablaré luego, por ser el grupo tal vez más interesante $y$, desde luego, menos difícil de documentar. En cuanto a los cuadros, los tasadores especificaron 64 lotes; por tanto, el número total de cuadros es bastante superior.

Los historiadores del arte podrán, quizá, identificar algunos de los cuadros inventariados, aunque éstos carezcan de pormenores; sin embargo, la

16 Cronica del gran Cardenal, pág. 465.

17 Salazar y Castro, Casa de Silva, pág. 578.

18 Cronica del gran Cardenal, pág. 465.

19 Archivo Histórico de Protocolos, Madrid: Juan Manrigue, Protocolo, 3361, fol. $648^{r}$. 
generalidad de los títulos hace cualquier identificación harto difícil. Solo se nombra a dos pintores en particular: un tal Cleves, pintor de "Quatro quadros grandes de Hermitaños del yermo" (núm. 8), y el beato dominico Luis Beltrán, que pintó a Santo Tomás con un Cristo en la mano (núm. 60). Pastrana parece haber sido devoto de este beato, pues poseyó también un libro sobre su vida y milagros (núm. 23 del inventario de los libros). Tal vez esta afición tenga que ver con su estancia en Roma: hacia 1622 Bartolomé de Aviñón, Provincial de los dominicos en Nápoles, viajó a Roma a procurar la canonización del beato Beltrán, y es posible que, teniendo en cuenta el nacimiento de Pastrana en Valencia (patria del beato), buscase el apoyo y la ayuda del Embajador español para este propósito.

Los primeros cuadros mencionados son retratos de familiares: sus hermanos Francisco y Diego (núm. 1); su abuelo Ruy Gómez de Silva, príncipe de Eboli (núm. 2); su padre (núm. 4), y un primo, el marqués de Almenara (núm. 3). Otros retratos son el número 10 (retrato de Felipe III con su mujer e hijos); el número 11 (retrato de Santa Isabel, reina de Portugal) los números 35, 41 y 43 (retratos del papa Urbano VIII y su sobrino el Cardenal Francisco Barberini), y, finalmente, los números 61 y 62 (retratos del Cardenal Coloma y del duque de Milán, Francisco Sforza). Estos últimos cuadros subrayan bien la influencia de la estancia en Roma desde 1623 hasta 1626 de Pastrana sobre sus gustos y amistades.

La categoría más representada entre sus cuadros es, naturalmente, dada la época, la religiosa: cuadros de la Santa Familia, de Cristo y de los Santos (unos 24 en total). Le siguen en importancia cuadros de temas históricos y míticos (el Senado de Venecia, el gran Turco, el Robo de Elena, etcétera), y, finalmente, cuadros de ermitaños, de pájaros y de navíos, y unos mapas. Un cuadro merece atención aparte, no tanto por su contenido (los cuatro elementos), sino por ser quien era su dueño anterior -don Rodrigo Calderón, marqués de Siete Iglesias, que fue ejecutado en la Plaza Mayor de Madrid en 1621. El inventario nos dice que Pastrana compró este cuadro en la almoneda pública de los bienes de Calderón.

La colección de cuadros del III duque de Pastrana es una colección que representa los intereses y gustos de un hombre tanto privado como de estado: cuadros de familiares y de pájaros (particular interés suyo, como demuestran los libros que tuvo sobre el género ${ }^{20}$, seguramente por haber sido Cazador Mayor de la Volatería) al lado de escenas bíblicas e históricas y níticas. A la vez es una colección que marca los hitos de su vida, de Flandes a Roma, de acompañante de su padre en asuntos militares hasta embajador en derecho propio, encargado de asuntos de los más delicados e intrincados.

20 Los números 37 ('Tres libros de aues de Rapiña en vn cuerpo pequeño) y 48 ( $V n$ libro de ystoria de aues en ytaliano). 
Tal arco iris de hechos y logros privados y públicos lo encontramos también con su colección de libros. Aquí ha sido posible identificar bastantes títulos, aunque no todos, y el resultado confirma la variedad de gustos e intereses de Ruy Gómez de Silva.

La mayoría de los títulos parece que tiene que ver con su estancia en Roma, o por lo menos demuestra una alta influencia italiana en su lectura: libros de entretenimiento de Torcuato Tasso, Ariosto, Lodovico Dolce, Tassoni, Petrarca, Bracciolini, Guarini ; libros de historia, de política o de arte militar de Frachetta, Crescentio, Guicciardini, Ramelli. Incluso tenía algunos textos clásicos traducidos al italiano, como las obras de Plutarco y Boecio, cuando existían buenas traducciones de ellas al español ${ }^{21}$. Tal inclinación por lo italiano se encuentra también con libros más modernos: Guillaume du Choul, Discorso della religione antica de' Romani (núm. 10), traducción al italiano preferida al texto francés o a la traducción al castellano de Baltasar Pérez del Castillo (Lyon, Guillelmo Rovillo, 1579) ${ }^{22}$; Pierre Matthieu, Historie della prosperità infelici di Elio Sejano (núms. 27 y 50), texto en francés originalmente; y, del mismo autor, Histoire de la Mort deplorable de Henry IIII., Roy de France (núm. 38), traducción al italiano preferida al texto original francés.

Está claro, por la variedad de libros italianos de historia, de geografía, de costumbres, que el duque de Pastrana quisó aprender cosas de su nueva patria, quiso meterse de pleno en la vida romana. También querría formar parte de la numerosa colonia de españoles residentes en la Santa Ciudad; así tuvo un ejemplar de los Estatutos de la Archicofradia de la SS. Resurrecion de Christo (núm. 88), cofradía fundada para los españoles en 1579 por Juan de Zúñiga, embajador español en Roma.

También se interesó por Venecia, y encontramos tres manuscritos sobre asuntos de la Serena República (núms. 5, 6 y 22). Los dos últimos fueron escritos por Alonso de la Cueva, marqués de Bedmar, más tarde Cardenal de la Cueva. Bedmar sirvió primero de embajador español en Venecia, hasta que pasó a ocupar la embajada en Bruselas. En el MS 2357 de la Biblioteca Nacional, Madrid (BNM) hay una carta de Pastrana al Cardenal escrita en Roma el 25 de enero de 1625, que trata de la pérdida de los pasos de la Valtellina, asunto de sumo interés para Bedmar, puesto que estaba al otro fin del Camino Español. En cuanto a los manuscritos que Pastrana poseyó de la mano de Alonso de la Cueva, no hay nada en los ejemplares de la $\mathrm{BNM}$ que indique que fueron alguna vez de su propiedad.

21 Sin embargo, otros textos clásicos sí que los leía en español: Transformaciones de obidio en lengua bulgar (núm. 35) y Aforismos de cornelio tacito (núm. 83).

22 P. Salví y Malden, Catálogo de la Biblioteca de Salvó, 2 vols., Valencia, 1872, II, núm. 3547. 
Otros títulos tratan de asuntos de Flandes (núm. 46) y de Francia (números 3, 18, 38 y 75), evidencia otra vez de su vida de caminante y, en el último caso, de plenipotenciario al servicio del rey. Aunque predominan títulos en italiano en este inventario, no faltan los escritos en su lengua nativa: libros de religión (núms. $23,26,63,70,72,89,91,92,93$ ); de historia (núms. 43, 52, 58, 71, 84); de política (núms. 4, 53, 64); de geografía (núms. 45, 59, 62, 73); de nobleza (núms. 21, 37,60,65, 66, 80, 90); de arte militar (núms. 61, 68).

Tampoco se puede pasar por alto su aparente habilidad lingüística, pues no sólo tenía libros en español, italiano y francés, sino también en portugués : números 54 y 78 (ambos de Francisco Rodrigues Lobo). ¿ Podemos achacar esto a la herencia dejada en la familia por Ruy Gómez de Silva, príncipe de Eboli, y portugués de nacimiento?

Finalmente, una palabra sobre un hecho realmente curioso: ¿ cómo es que Pastrana poseía cuatro libros prohibidos, los números $24,29,32$ y 70 ? Una biblia en castellano, dos libros de juego y un libro "de menosprecio de los dioses en ytaliano" que no he podido identificar. Además, tenía un manuscrito del Maestro Pasquino, autor que aparece dos veces en el Index librorum prohibitorum. Tal vez su calidad de noble le protegía de las actividades inquisitoriales en materia de lecturas prohibidas. En este aspecto, es interesante observar que en un inventario de los libros del duque de Pastrana hecho a principios del siglo xvirI figura cantidad de libros prohibidos.

Tanto los libros como los cuadros de Ruy Gómez de Silva, III duque de Pastrana revelan, entonces, una personalidad polifacética: bien versado en la política y lo militar, no descuidaba la formación humanística por concentrarse solamente en lo práctico y lo útil. El que poseyese textos de Tasso, Ariosto y Petrarca es buena prueba de su interés por la literatura propiamente dicha. Desde cualquier ángulo, parece haber sido un noble instruido y culto, y, como es bien sabido, España no estaba precisamente inundada de tales aristócratas en el primer tercio del siglo xvir. Con su temprana muerte en 1626 España perdió a uno de sus procónsules más prometedores.

\section{INVENTARIO DE LOS CUADROS}

[1] Dos retratos de los señores don fran[cis]co y don diego de silba Pequeños sin marco.

[2] Otro Retrato guarnecido de hebano del Principe Ruy gomez de Silba de medio cuerpo con su marco de heuano.

[3] Otro Retrato del Marques de Almenara don yñigo con su auito de santiago. 
[4] Otro Retrato del duque Don Rodrigo de medio cuerpo con su marco.

[5] Vn quadro de los quatro elementos guarnecido de heuano y con vna cortina de tafetan açul que se compro de la Almoneda de Don Rodrigo calderon.

[6] Quince Payses de los Hermitaños del yermo con sus marcos dorados y negros. [fol. $661^{\text {r }}$ ]

[7] Otro Pais grande con su marco.

[8] Quatro quadros grandes de Hermitaños del yermo que pinto cleues sin marcos.

[9] Vn mapa grande de flandes.

[10] Vn quadro del Retrato del Rey felipe tercero con sus Hijos y muger con el marco dorado.

[11] Otro quadro de santa ysauel Reyna de Portugal con el marco negro y dorado.

[12] Vn quadro de la coronacion de nuestra señora mediano.

[13] Otro quadro de san fran[cis]co de sise entero.

[14] Vn quadro de san geronimo con antojos.

[15] Otro quadro de san sebastian con cinco flechas.

[16] Otro quadro del transito de nuestra señora con san Pedro en la parte de abajo.

[17] Otro quadro de nuestra señora de marco menor con san Joseph y el niño en los braços desnudo.

[18] Otro quadro de la encarnacion pequeño.

[19] Otro quadro de san sebastian sin flechas con vn braço atado y otro caydo.

[20] Vn quadro de nuestra señora con su hijo que tiene vn anillo en la mano.

[21] Otro quadro de la adoracion de los Reyes.

[22] Otro de mathias y san fran[cis]co con su conpañero a los pies. [fol. $\left.661^{v}\right]$

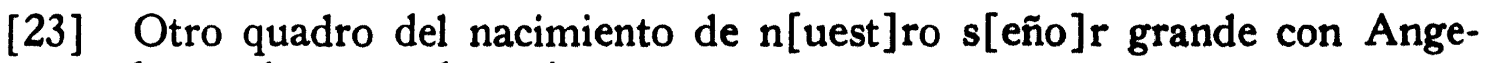
les en la parte de arriua. 
[24] Otro quadro de la conuersion de san mateo grande.

[25] Otro quadro grande con el trihumpho de ninphas.

[26] Otro quadro de vna nimpha mediano que se esta tocando y cupido le tiene el espejo.

[27] Otro quadro mediado del senado de venencia.

[28] Otro quadro mediado de la cena del Rey baltasar.

[29] Otro quadro de vna gitana con vn niño en los braços.

[30] Otro quadro de la piedad Romana que da de mamar a su padre.

[31] Otro quadro mas pequeño de la misma historia.

[32] Otros dos quadros de dos philosophos con el mundo abajo que le hazen entero juntos.

[33] Doze sibilas medianas.

[34] Nueue Retratos de mugeres Romanas pequeños.

[35] Dos Retratos el vno del papa Vrbano octauo y el otro de su sobrino.

[36] Vn quadro de vn christo viuo.

[37] Otro quadro de vn christo muerto.

[38] Vn quadro de vn Christo pequeño con nuestra señora.

[39] Dos quadros de los santos el vno con vna sierra y el otro con vn cartabon. [fol. 662r]

[40] Seis quadros de Nauios y galeras grandes.

[41] Vn quadro del Papa a cauallo acompañado de caualleria.

[42] Otro quadro del gran Turco.

[43] Otro quadro del sobrino del papa cardenal.

[44] Vn quadro de vn ece homo con su cerco de peral negro.

[45] Vn quadro de nuestra señora con su Hijo y vn paxarillo en la mano con el marco dorado pintado en tabla.

[46] Otro quadro de nuestra Señora Pintado en tabla guarnecido de heuano en rredondo. 
[47] Otros dos quadros pintados en piedra vnos hermitaños con sus cercos dorados.

[48] Vna pintura en piedra pintado vn biejo y vna nimpha con su cerco dorado y negro.

[49] Vn quadro de vna caueza de vn biejo con su cerco de peral negro pintado en lienço.

[50] Otro quadro de santa lucia Pintada en tabla.

[51] Otros quadros de vnos fuegos de Roma pintados en tabla con sus marcos dorados por de fuera açul y blanco.

[52] Otro quadro del Robo de elena con su cerco dorado Pintado en tabla y es a obalo.

[53] Catorce mapas de papel pequeños que estan en chamartin. [fol. $662^{v}$ ]

[54] Vn quadro de vna lucrecia con vn pañal en la mano Pintada en piedra con su cerco de madera negra que esta quebrado.

[55] Otro quadro de la madalena Pequeño pintada en piedra y Hechada y vna cruz en la mano con su cerco negro y listado de marfil.

[56] Otro quadro de san juan de la misma guarnicion y esta quebrado.

[57] Quatro Piedras Pequeñas de pajarros aforradas en piçarra.

[58] Quatro obalos grandes pintados vnos pajaros de diferentes maneras con cercos de papelon dorado y esta el cerco del vno quebrado.

[59] Veynte y quatro obalos mas pequeños de pajaros con sus cercos de papelon dorado.

[60] Vn quadro de santo Tomas con su cerco dorado y negro con vn christo en la mano digo que es del beato ludobico beltran del orden de santo Domingo.

[61] Vn quadro pequeño sin marco del cardenal colona que tiene su letrero.

[62] Vn quadro de fran[cis]co esforça duq[u]e de milan con su letrero sin marco.

[63] Otro quadro Pequeño de vn turco sin marco.

[64] Vn quadro de Santa sicilia Pintada sobre vn espejo y guarnecido de heuano obado dentro y guarnecido de bronce dorado y Plata con su caxa colocada argentada. [fol. $663^{r}$ ] 


\section{INVENTARIO DE LOS LIBROS ${ }^{23}$}

[1] Vnas oras del oficio de difuntos aforradas en capa con vna manecilla de oro esmaltada.

[2] Vn libro del tasso de la Jerusalen libertada.

Torquato Tasso, La Gerusalemme liberata, ouero il Goffredo, Parma, E. Viotto. 1581 (Johnson-Scholderer, pág. 660; Solís, pág. 112).

23 He transcrito este inventario tal y como ha llegado a nosotros, intercalando entre cada título el autor, título completo, impresor y lugar y fecha de impresión de la primera edición conocida de los ejemplares localizados. Para completar la información dada, indico la fuente de las noticias bibliográficas, utilizando para ello las tipobibliografías más generalizadas. Se citan abreviadamente un conjunto de obras que son las que siguen:

Alcocer = Mariano Alcocer y Martínez, Catálogo razonado de obras impresas en Valladolid (1481-1800), Valladolid, 1926.

Beardsley = Theodore S. Beardsley, JR., Hispano-Classical Translations Printed Between 1482 and 1699, Duquesne University Press, 1970.

BLGC = The British Library General Catalogue of Printed Books to 1975, 342 vols., London, 1979-86.

Catalina García = Juan Catalina García, Ensayo de una tipografía complutense, Madrid, 1889.

Escudero $=$ Francisco Escudero y Perosso, Tipografía hispalense. Anales bibliográficos de la ciudad de Sevilla desde el establecimiento de la imprenta hasta fines del siglo XVIII, Madrid, 1894.

Goldsmith $=$ V. F. Goldsmith, A Short Title Catalogue of Spanish and Portuguese Books 1601-1700 in the Library of the British Museum, Londres, 1974.

Inca Garcilaso = José Durand, "La biblioteca del Inca", Nueva Revista de Filología Hispánica, II (1948), págs. 239-264.

Johnson-Scholderer = A. F. Johnson \& V. Scholderer, Short-title Catalogue of Books printed in Italy and of Italian Books printed in other countries from 1465 to 1600 now in the British Museum, Londres, 1958.

Lastanosa = KarL-Ludwig Selig, The Library of Vincencio Juan de Lastanosa, Patron of Gracián, Genève, 1960.

Mendoza = "La biblioteca de Mendoza", en Anger González Palencia y Eugenio Mele, Vida y obras de don Diego Hurtado de Mendoza, Madrid, 1943, III, páginas 481-572.

Norton $=$ F. J. Norton, A Descriptive Catalogue of Printing in Spain and Portugal 1501-1520, Cambridge, 1978.

Palau = Antonio Palau y Dulcet, Manual del librero hispano-americano, 28 vols., Barcelona, 1948-77.

Peeters-Fontainas = Jean Peeters-Fontainas, Bibliographie des impressions espagnoles des Pays-Bas méridionaux, 2 vols., Nieuwkoop, 1965.

Penney = Clara Louisa Penney, Printed Books $1468-1700$ in the Hispanic Society of America, New York, 1965.

Pérez Pastor, Madrid = Cristóbal Pérez Pastor, Bibliografía madrileña, 3 vols., Madrid, 1891-1907.

Pérez Pastor, Toledo = Cristóbal Pérez Pastor, La imprenta en Toledo. Descripción bibliográfica de las obras impresas en la imperial ciudad desde 1483 hasta nuestros días, Madrid, 1887. 
[3] Otro libro de la memoria de phelipe de comes.

El autor y la obra en cuestión (en edición italiana) son: PHILIPPE DE CoMINES, La historia delle guerre $\mathcal{E}$ costumi di Ludouico undecimo re di Francia, Venecia, M. Tramezino, 1544 (Johnson-Scholderer, pág. 192). Hubo una edición española en 1643 con el siguiente título: Las memorias de Felipe de Comines, Señor de Argenton, de los hechos y empresas de Luis vndecimo y Carlos octavo... Traducidas por don Iuan Vitrian, Amberes, Juan Meursio, 1643 (Peeters-Fontainas, núm. 266). Lastanosa se refiere a una edición de 1582: Felipe Comines, Compendio de sus memorias (núm. 264), y Ramírez de Prado tuvo el siguiente ejemplar: Memorias de Comines, señor de Argenton, del Rey Luis XI y Carlos VIII en Italiano, Milán, 1610 (Ramírez de Prado, II, pág. 214). No tengo datos sobre esta edición que, por su título, se asemeja mucho a la que poseyó Pastrana (véase también Salinas, núm. 74 ; Solís, pág. 129).

[4] Otro libro Pequeño de obseruacion destado.

Acaso Pierre Matthieu, Osseruationi di stato, e di historia sopra la vita, $e$ i seruigij del Signor di Villeroy, Venetia, Gio. Battista Ciotti, 1619 (Rhodes, pág. 558). Nótese que es un libro en $24^{\circ}$.

Ramírez de Prado = Joaquín de Entrambasaguas, La biblioteca de Ramirez de Prado, 2 vols., Madrid, 1943.

Rhodes = D. E. Rhodes (ed.), Catalogue of Seventeenth Century Italian Books in the British Library, 3 vols., London, 1986.

Salazar = Jean-Michel Lasperas, "La biblioteca de Cristóbal de Salazar, humanista y bibliófilo ejemplar", Criticón, 22 (1983), págs. 5-132.

Salinas $=$ T. J. Dadson, "La biblioteca del poeta y político Diego de Silva y Mendoza, Conde de Salinas (1564-1630)", El Crotalón. Anuario de Filología Española, III (1986; en prensa).

Salvá = Pedro Salvá y Mallen, Catálogo de la Biblioteca de Salvá, 2 vols., Valencia, 1872.

Simón Dfaz, Autores extranjeros = Josł Simón Dínz, "Autores extranjeros traducidos al castellano en impresos publicados durante los siglos xv-xvin", Cuadernos Bibliográficos, 40 (1980), págs. 23-52.

Simón Dfaz, $B L H=$ José Simón Dfaz, Bibliografía de la literatura hispánica, 14 vols., Madrid, 1950-84 [en preparación].

Simón Dfaz, Mil biografías = José Simón Dłaz, Mil biografías de los siglos de oro (Indice bibliográfico), Madrid, 1985.

Solfs = F. Serralta, "La biblioteca de Antonio de Solís", Cahiers du Monde Hispanique et Luso-brésilien (Caravelle), 33 (1979), págs. 103-132.

STC Italy = Short-Title Catalog of Books Printed in Italy and of Books in Italian Printed Abroad 1501-1600 Held in Selected North American Libraries, 3 vols., Boston, 1970.

Tномаs $=$ H. Thомаs, Short-title Catalogue of Books printed in Spain and of Spanish Books printed elsewhere in Europe before 1601 now in the British Museum, Londres, 1921.

TODA I GüEll = EDUART TODA I GǘlL, Bibliografia espanyola d'Italia dels origens de la imprempta fins a l'any 1900, 5 vols., Castell de Sant Miquel d'Escornalbou, 1927-31.

VÁzQUEz DE LECA = "The Catalogue of M[ateo] V[ázquez]'s Books" in A. W LoVETT, Philip II and Mateo Vdsquez de Leca: the Government of Spain (1572-1592), Genève, 1977, págs. 128-38. 
[5] Vn libro grande de la antigue[da]d y ystoria de benecia escripto a mano en lengua ytaliana.

[6] Vn libro escripto a mano de las cossas de benecia escripto en ytaliano por don Alonso de la cueba.

Alonso de la Cueva, marqués de Bedmar, "Relatione della cose di Venetia / Fatta da D. Alfonso della Cueua Ambas. ${ }^{\text {re }}$ di Spag. ${ }^{a}$ hoggi Cardinale", BNM MS 9269 (Simón Díaz, BLH, IX, núm. 1720). Hay dos versiones más en la Biblioteca Marucelliana de Florencia (Simón Díaz, $B L N$, IX, núms. 1721 y 1723). Véase también abajo núm. 22.

[7] Vn libro de muchos descriuir ytaliano.

Tal vez Sigismondo Fanti, Theorica et practica... de modo scribendi, Venetia, J. Rubeum, 1514 (Johnson-Scholderer, pág. 243 ; Salazar, núm. 375).

[8] Las obras morales de Plutarco en lengua ytaliana Primera y segunda Parte.

Plutarco, Opusculi morali, trad. de M. A. Gandino et al., 2 partes, Venetia, F. Prati, 1598 (Johnson-Scholderer, pág. 660).

[9] Seminario de gouierno destado y guerra de geronimo fraqueta en ytaliano.

Girolamo Frachetta, Il seminario dégoverni di stato e di guerra, Venetia, Euangelista Deuchino, 1617 (Rhodes, pág. 355 ; Solís, pág. 112).

[10] Vn libro de discurso de la Religion antigua de Romanos en ytaliano con figuras.

Guillaume du Choul, Discorso della religione antica de' Romani, con un altro discorso della castrametatione, trad. de G. Simeoni, Lione, G. Rouillio, 1559 (Johnson-Scholderer, pág. 228; Solís, pág. 112).

[11] Otro de las yslas mas famosas del mundo con figuras de geographia en lengua ytaliana.

Cf. el siguiente título: Islas dibujadas $i$ coloridas de mano con explicacion en italiano impresa en Roma el año 1493 en $4^{\circ}$ (Lastanosa, núm. 564).

[12] Vn libro del ariosto en ytaliano.

Con tan poca información, podría tratarse de cualquier título de LoDovico Ariosto, pero el candidato más firme ha de ser su Orlando furioso, Ferrara, G. Mazocco, 1516 (Johnson-Scholderer, pág. 38). Nótese que Pastrana también poseyó las Rimas y sátiras de Ariosto (núm. 87 abajo).

[13] Raçonamientos del parnaso en lengua ytaliana. [fol. 681' ]

Trajano Boccalini. De' Ragguagli di Parnaso, Venetia, P. Farri, 1612 (Rhodes, pág. 119; Lastanosa, núms. 96 y 939; Solís, pág. 130). 
[14] La gerusalen conquistada de Torquato Taso en lengua ytaliana.

Torquato Tasso, Di Gerusalemme conquistata, Roma, G. Facciotti, 1593 (Johnson-Scholderer, pág. 660; Solís, pág. 128).

[15] La nauegacion de crecencio del mar mediterraneo en lengua ytaliana. Bartolomeo Crescentio, Nautica mediterranea... Nella quale si mostra la fabrica delle galee', 2 partes, Roma, B. Bonfadino, 1607 (Rhodes, pág. 272).

[16] Vn libro de aquiles y elena de ludobico Dulce en ytaliano.

Lodovico Dolce, L'Achille et l'Enea. Aggiuntoui una oratione del s. Andrea Menechini sopra le lodi della poesia, Vinegia, G. Giolito, 1571 (Johnson-Scholderer, pág. 219; Ramírez de Prado, II, pág. 63).

[17] La gerusalen figurada de Torquato tasso en ytaliano.

Torquato Tasso, La Giersulamme del Signor Torquato Tasso. Con gl'argomenti del Sig. G. V. Imperiale; figurata da B. Castello, Genova, G. Pavoni. 1604 (Rhodes, pág. 893).

[18] Ensayos y Prueuas de miguel de montaña Traducido de frances en español $=\mathrm{y}$ son tres Libros primera segunda y tercera parte.

Se trata de los Essais de Michel De Montaigne; la edición de 1588 es la primera edición francesa en tres partes. Sin embargo, no he podido encontrar referencia bibliográfica alguna a una traducción al español de esta célebre obra.

[19] El guchardino ystoria de ytalia Primera y segunda Parte en quarto de Pliego.

Francesco Guicciardini, L'Historia d'Italia, 2 partes, en $4^{\circ}$, Vinegia, G. Giolito, 1567 (Johnson-Scholderer, pág. 320; Inca Garcilaso, núm. 133; Solís, pág. 127; Vázquez de Leca, pág. 134).

[20] La philipica de cosas despaña.

Tal vez se trate de Alessandro Tassoni, Filippica, 1615 (Rhodes, pág. 342), obra en contra de Felipe III y el gobierno español en Nápoles.

[21] Vn libro de frenos y enfrenar.

Cf. Eugenio Manzanas, Libro de enfrenamientos de la gineta, Toledo, Francisco de Guzmán, 1570 (Salvá, núm. 2638; Pérez Pastor, Toledo, número 322), y Francisco Pérez de Navarrete, Arte de enfrenar, Madrid, Juan González, 1626 (Salvá, núm. 2660; Ramírez de Prado, II, pág. 106).

[22] Vn libro de instrucion del marques de belmar a su sucesor en benecia escripto a mano.

"Instrucción dada por el Marques de Bedmar embajador de S. M. Catholica en Venecia a Don Luis Brabo su sucesor acerca del modo conque se ha de governar en su embajada", BNM MS 6662, fols. 162-187 (Simón 
Díaz, $B L H$, IX, núm. 1719). El marqués de Bedmar era don Alonso de la Cueva, más tarde Cardenal de la Cueva y embajador de España en Bruselas.

[23] La vida y milagros del beato Luys veltran.

Tal vez BARtomeu Aviñón, Vita virtu e miracoli del Beato Luigi Bertrando del Ordine de Predicatori, Roma, Alfonso Ciaccone, 1623 (Toda i Güell, núm. 440; Simón Díaz, BLH, VI, núm. 1756). Aviñón fue a Roma a solicitar la canonización del beato Luis Beltrán, durante la época en que Pastrana fue embajador allí. Véase también el núm. 60 del inventario de los cuadros, retrato de Santo Tomás hecho por el Beato Luis Beltrán de la Orden de Santo Domingo.

[24] Vn libro de menosprecio de los dioses en ytaliano.

En margen: "es vedado no se tasa".

[25] Tesoro de salud en ytaliano.

Castore Durante de Gualdo, Il Tesoro della sanità, Venetia, A. Muschio, 1586 (Johnson-Scholderer, pág. 230 ; Lastanosa, núm. 153).

[26] Vn libro de la Religion de san agustin de fr. Juan marquez. [fol. 681v] Fr. Juan Márquez, Origen de los frayles ermitaños de la Orden de San Avgrstin, y su verdadera institvcion antes del gran Concilio Lateranense, Salamanca, Antonia Ramírez, 1618 (Simón Díaz, BLH, XIV, núm. 2165).

[27] Vn libro de la ystoria de helioseyano de Prosperidad infeliçe en ytaliano.

Pierre Matthieu, Historie della prosperitd infelici di Elio Sejano, e d'una femina di Catanea gran Siniscalca di Napoli... tradotte dalla Francese nella lingua Italiana dal Gelato Academico Humorista, 2 partes, Milano, Gio. Battista Bidelli, 1620 (Rhodes, pág. 558).

[28] Vn libro que se intitula vegecio de cosas de guerra en ytaliano.

Flavius Vegetius Renatus, De l'arte militare, trad. de T. Gaetano, Venesia, G. de Gregorii, 1525 (Johnson-Scholderer, pág. 713; Solís, pág. 117).

[29] Vn libro de juego Por discurssos en lengua ytaliana.

En margen: "Esta vedado no se tasa". Tal vez sea Lorenzo Spirito, Libro delle sorti; hay edición española: Libro del juego de las Suertes, Valencia, Jorge Costilla, 1515 (Norton, núm. 1233). Fue prohibida la impresión de este libro de juego en cualquiera lengua en el Indice español de 1559 (véase F. J. Norton, Printing in Spain, 1501-20, Cambridge, 1966, pág. 88).

[30] Raçonamientos de Pasquino y marforio en lengua ytaliana de mano. Tal vez se trate de un manuscrito del siguiente impreso: Maestro PasquiNo DI PARIONE, Compositioni nuoue tradotte di Latino in volgare da Marforio suo carissimo cõpagno antico, ¿ Roma?, 1547 (STC Italy, II, pág. 528). 
Dos textos del Maestro Pasquino y su compañero Marforio acabaron en el Index Librorum Prohibitorum: Pasquini \& Marphorii hymnus in Paulum III y Il Puttanismo Romano overo Conclave generale delle puttane della Corte. Cui annectitur alius libellus, cui titulus: Dialogo trà Pasquino, e Marforio sopra l'istesso soggetto.

[31] Vn libro de berdadera Raçon de la buena salud escripto a mano.

[32] La gesta [isic?] cueba de marlota en lengua ytaliana libro de juego. En margen: "vedado". Tal vez se refiera a Augustinus Marloratus, autor prohibido en el Indice romano de libros prohibidos. Al mismo tiempo, se prohibiría el libro por tratarse de un libro de juego, género terminantemente prohibido en todos los índices. Véase el número 29 abajo.

[33] Boecio de consolacion en lengua ytaliana.

Boethius, Della consolazione della filosofia, trad. de B. Varchi, Firenze, L. Torrentino, 1551 (Johson-Scholderer, pág. 114).

[34] Vn libro de la vida de santa ysauel Reyna de Portugal.

Probablemente se trata del siguiente anónimo: Vida de la gloriosa Santa Isabel, Reyna de Portugal. Buelta de Toscano en español por Juan Antonio de Vera y Zúñiga, Roma, Jacomo Mascardi, 1625 (Simón Díaz, Mil biografías, núm. 332; Ramírez de Prado, II, pág. 219). Nótese que Pastrana tuvo un retrato de la reina Isabel (núm. 11 del inventario de cuadros). Es probable que se deba el interés de Pastrana en esta santa al hecho de que fue canonizada mientras él estaba en Roma.

[35] Transformaciones de obidio en lengua bulgar

Es probable que se trate de la siguiente edición: P. Ovidio Nasón, Las Metamorphoses, o Transformaciones del muy excelente poeta Ouidio... traduzidas en Castellano, trad. de Jorge de Bustamante, Amberes, Juan Steelsio, 1551 (Peeters-Fontainas, núm. 1013; Beardsley, núm. 42). Para las traducciones de Ovidio, véase Simón Díaz, Autores extranjeros, págs. 44-45.

[36] El Pastor fido en lengua ytaliana.

Giovanni Battista Guarini, Il pastor fido. Tragicomedia pastorale, Venetia, G. B. Bonfadino, 1590 (Johnson-Scholderer, pág. 317; Solís, página 128).

[37] Tres libros de aues de Rapiña en vn cuerpo pequeño.

Cf. el siguiente título de la biblioteca de M. Vázquez de Leca: Los tres libros de los pájaros de rapiña y de los perros en Venecia año de $15684^{\circ}$ $y$ pargo $^{\circ}$ (pág. 132).

[38] Historia de la muerte de enrique quarto en ytaliano.

La obra original es de Pierre Matthieu, Histoire de la Mort deplorable de Henry IIII., Roi de France, 2 partes, Paris, 1611 (BLGC, vol. 215, pá- 
gina 265). Hay traducción española de Juan Pablo Mártir Rizo: Pedro Mateo, Historia de la muerte de Enrico el Grande, Quarto Rey de Francia deste nombre, Segovia, Diego Flamenco, 1628 (Salvá, núm. 3471). Sin embargo, no he encontrado una traducción al italiano de esta obra antes de 1630. Véase Simón Díaz, Autores extranjeros, pág. 43.

[39] Vn libro de la seca Rapida en ytaliano.

Alessandro Tassoni, La Secchia Rapita, poema eroicomico, Roma, N. Ronciglione. 1624 (Rhodes, pág. 896).

[40] Vn libro de la fabula Rustica en poema ytaliano. [fol. $682^{r}$ ]

Tal vez sea Angelo Ambrogini [Poliziano], Angelo Politiani Silua: cui titulus Rusticus in poetae Hesiodi Vergilioe georgicon ennarratione pronunciata, Florentiae, Antonius Miscominus, 1492 (BLGC, vol. 6, pág. 515).

[41] Vn libro de siete ojas de piçarras dorado en escriptura con cubiertas coloradas.

[42] Prohemio de triunpho de fortuna figurada en ytaliano.

Acaso Sigrsmondo Fanti, Triompho di Fortuna, Venegia, Agostin da Portese, 1527 (Johson-Scholderer, pág. 243).

[43] Vn libro teatro de las grandeças de madrid en español.

Gil González Dávila, Teatro de las grandezas de la Villa de Madrid Corte de los Reyes Catolicos de España, Madrid, Tomás Junti, 1623 (Salvá, núm. 2971; Pérez Pastor, Madrid, núm. 1943; Goldsmith, G259; Solís, pág. 111).

[44] Treato del mundo en castellano.

Será o Pedro Bovistán, El Theatro del mundo. En el cual amplamente se trata de las miserias del hombre, trad. de Baltasar Pérez del Castillo, Alcalá, Andrés de Angulo, 1564 (Catalina García, núm. 356; Inca Garcilaso, número 187 ; Vázquez de Leca, pág. 131) o Grovanni Paolo Galluci, Theatro del Mundo y de el Tiempo, trad. de Miguel Pérez, Granada, Miguel Pérez, 1606 (Penney, pág. 220 ; Goldsmith, G16; Inca Garcilaso, núm. 187 ; Solís, pág. 112; Ramírez de Prado, II, pág. 99 [ed. de 1598]).

[45] Vn libro de Mapas sin ystoria.

[46] Discrecion de los Payses bajos de flandes.

Será o Pedro Cornejo, Origen de la civil disension de Flandes, Turín, Herederos de Bebilaqua, 1580 (Toda i Güell, núm. 1346; Penney, pág. 149; Simón Díaz, BLH, IX, núm. 317) o Lodovico Guicciardini, Descrittione di tutti $i$ Paese Bassi, Anversa, G. Silvio, 1567 (STC Italy, II, pág. 106; Johnson-Scholderer, pág. 321 ; Solís, pág. 112; Vázquez de Leca, pág. 133) o Emanuel Sueyro, Descripcion breve del Pais Baxo, Anvers, Gérard Wolsschaten, 1622 (Peeters-Fontainas, núm. 1249; Ramírez de Prado, II, pág. 219). 
[47] Tercero y quarto libro de arquitectura de sebastian serlio.

Sebastiano Serlio, Tercero y Quarto Libro de Arquitectura de Sebastian Serlio Boloñes. En los quales se trata de las maneras de como se pueden adornar los hedificios: con los exemplos de las antiguedades. Agora nuevamente traduzido de Toscano en Romance Castellano por Francisco de Villalpando Architecto, Toledo, Juan de Ayala, 1552 (Pérez Pastor, Toledo, núm. 297).

[48] Vn libro de ystoria de aues en ytaliano.

Cf. Diego de Funes y Mendoza, Historia general de las aves y animales, Valencia, 1621 (Salvá, núm. 2704; Lastanosa, núm. 210) y el popular PreRRE BELON, L'Histoire de la nature des oyseaux auec leurs descriptions, Paris, B. Prevost, 1555 (BLGC, vol. 24, pág. 295).

[49] Vn libro de profecia del abad Joaquin.

Joachinus (Abad de Fiore), Vaticinia siue prophetiae Abbatis Ioachimi $\mathcal{E}$ Anselmi Episcopi Marsicani, Venetiis, H. Porrum, 1589 (Johnson-Scholderer, pág. 356). En margen: "no bale nada".

[50] Historia de la prosperidad ynfeliçe de helioseyano.

Véase el núm. 27 arriba.

[51] Las vidas de Plutarco en lengua ytaliana.

Plutarco, Le uite de gli huomini illustri greci et romani, ed. F. Sansovino, 2 partes, Venetia, V. Valgrisi, 1564 (Johnson-Scholderer, pág. 529; Solís, pág. 127).

[52] Vn libro de Argenis del Touar.

José Pellicer de Osau Salas y Tovar, Argenis, 2 partes, Madrid, Luis Sánchez, 1626 (Salvá, núm. 1713 ; Palau, núm. 216693 ; Penney, pág. 51 ; Lastanosa, núms. 65 y 529). El autor de la obra original es John Barclay. Véase Simón Díaz, Autores extranjeros, pág. 26.

[53] El embajador de don juan antonio de vera.

Juan Antonio de Vera y Zú̃̃iga, El Enbaxador: dividido en cuatro discursos, Sevilla, Francisco de Lira, 1620 (Salvá, núm. 4034 ; Escudero, número 1206; Goldsmith, V382 ; Lastanosa, núm. 510).

[54] Vn libro condestable de portugal de francisco Rodriguez Portugues. Francisco Rodrigues Lobo, $O$ condestable de Portugal, d. Nuno Alures Pereira, Lisboa, Pedro Crasbeeck, 1610 (Goldsmith, R167).

[55] Epilogo de treato [sic] del mundo figurado pequeño.

¿Véase abajo núm. 44? Entre los libros confiscados a don Alonso Ramírez de Prado en 1611 figura el siguiente: Teatro del mundo, iluminado y encua- 
dernado en becerro, in folio, en un cuerpo (GREGoRIo DE ANDRÉs, "Los libros confiscados a don Alonso Ramírez de Prado (1611)”, núm. 94).

[56] Vn libro latino en defensa de los sacramentos contra luteranos.

[57] Tratado del Radio latino ynstrumento de medidas. [fol. $682^{v}$ ]

[58] Vn libro de la vida de carlos quinto.

Podía tratarse de Alfonso de UlloA, La vita dell'imperator Carlo quinto, Venetia, V. Valgrisi, 1560 (Johnson-Scholderer, pág. 704 ; Lastanosa, número 84) o, más probablemente, de JuAn Antonio de Vera y Zúñiga, Epitome de la vida $i$ hechos del invicto Emperador Carlos $V$, Madrid, Viuda de Alonso Martín, 1622 (Pérez Pastor, Madrid, núm. 1906; Goldsmith. V383).

[59] Vn libro largo de mapas.

[60] Vn libro de como se arma vn cauallero del auito de santiago.

Es posible que se trate aquí de una de las muchas compilaciones de las reglas de la orden de Santiago impresas durante el siglo XVI: JuAN FernánDEZ DE LA GAMA: Cõpilacion de los establecimientos de la orden de Caballeria de Santiago de la Espada, Sevilla, Juan Pegnicer de Nuremberga, 1503 (Escudero, núm. 132; Norton, núm. 729) o García de Medrano, Regla y establecimientos de la cavalleria de Santiago del Espada, Valladolid, Luis Sánchez, 1603 (Alcocer, núm. 437).

[61] Vn libro arte de las armas.

Achille Marozzo, Arte dell'Armi, Venetia, A. Pinargenti, 1568 (JohnsonScholderer, pág. 418; Lastanosa, núm. 93).

[62] Vn libro grande del teatro del orbe de la tierra en castellano. [fol. $\left.683^{r}\right]$

Abraham Ortelius, Theatro d'el orbe de la tierra, Anveres, Oficina Plantiniana, 1602 (Peeters-Fontainas, núm. 991 ; Lastanosa, núm. 5).

[63] Otro libro yntitulado bocabulario de la orazion.

[64] Otro libro yntitulado gouernador Xpano.

Fr. Juan MárQuez, El Governador Christiano deducido de las Vidas de Moysen, y Josue, Salamanca, Francisco de Cea Tesa, 1612 (Simón Díaz, $B L H$, XIV, núm. 2145). Hay edición madrileña de Teresa Junti, 1625 (Salvá, núm. 3943 ; Pérez Pastor, Madrid, núm. 2180 ; Goldsmith, M106).

[65] Otro libro yntitulado Penachos y celadas.

[66]. Otro libro yntitulado ynbenciones de frenar.

[67] Vn libro de Mapas de ytalia. 
[68] Otro libro de fortificacion.

Tal vez sea o Cristóbal Lechuga, Discurso... en que se trata de la Artillería y de todo lo necesario a ella. Con un tratado de fortificacion, y otros aduertimientos, Milán, Marco Tulio Malatesta, 1611 (Toda i Güell, número 2709; Simón Díaz, $B L H$, XIII, núm. 39; Salinas, núm. 68), o Drego González de Medina BARBa, Examen de fortificacion, Madrid, Licenciado Várez de Castro, 1599 (Salvá, núm. 2626; Pérez Pastor, Madrid, número 624), o CRISTÓBAL DE RoJAS, Teorica y practica de fortificacion, conforme las medidas y defensas destos tiempos, Madrid, Luis Sánchez, 1598 (Salvá, núm. 2667 ; Pérez Pastor, Madrid, núm. 603).

[69] Otro libro de diuersas maquinas del capitan agustino Rameli en lengua ytaliana.

Agostino Ramelli, Le diuerse et artificiose machine, Parigi, A. Ramelli, 1588 (Johnson-Scholderer, pág. 548).

[70] Otro libro de la bliblia [sic] en Romance.

En margen: "Libro vedado". Es probable que sea una de las ediciones traducidas por CASIOdoRo DE Reina, La Biblia, que es los sacros libros del viejo y nuevo Testamento. Trasladada en Español, Basilea, Tomás Guarino, 1569 (Salvá, núm. 3847). Casiodoro de Reina apareció en el primer Indice romano de libros prohibidos.

[71] Otro libro yntitulado esplendor de la antigua Roma.

Tal vez sea o Andreas Fulvius, Opera delle antichità della città di Roma, Venetia, 1588 (Johnson-Scholderer, pág. 283 ; Inca Garcilaso, núm. 122) o Paolo Manuzio, Antiquitatum Romanorum liber, Venetia, Aldus, 1559 (Johnson-Scholderer, pág. 412 ; Inca Garcilaso, núm. 180) o Bernardo GAMUCCI, Le antichita della citta di Roma, Vinegia, G. Varisco, 1569 (JohnsonScholderer, pág. 290). Nótese también Pietro MartiRe Felini, Tratado nuevo de las cosas maravillosas de la alma ciudad de Roma, adornado de muchas figuras... Traduzido en lengua Española por... A. Muñoz, Roma, 1610 (BLGC, vol. 106, pág. 506).

[72] Otro libro yntitulado trihumpho de Xpo crucificado.

[73] Otro libro del viaje del Marques de Tarifa.

FAdrique EnRíquez dE Ribera, Este libro es del viage que hize a Ierusalem. de todas las cosas que en el me pasaron desde que sali de mi casa de Bornos, miercoles 24 de Nouiembre de 518, hasta 20 de Otubre de 520 que entre en Seuilla Yo Don Fadrique Enriquez de Rivera primer marques de Tarifa, Sevilla, Francisco Pérez, 1606 (Salvá, núm. 571; Escudero, número 908 ; Simón Díaz, $B L H$, IX, núm. 4651 ; Goldsmith, E38). La primera edición es de Lisboa, 1580 (Anselmo, núm. 1267).

[74] Otro libro yntitulado Pompontauricus.

Posiblemente Guillermo Rovilio, Primera parte del Promptuario de las medallas de todos los mas insignes varones que ha auido desde el principio 
del mundo, trad. de Juan Martín Cordero, Lyon, G. Rovillio, 1561 (Salvá, núm. 3590 ; Penney, pág. 483). Nótese también Promptuarium linguae latina tomos duos divisa auth., Basileae, 1545 (Salazar, núm. 282).

[75] Otro libro de ystorias de francia.

Tal vez sea Antonio de Herrera y Tordesillas, Historia... de los sucesos de Francia, desde el año de 1585. que començó la liga Catolica, hasta el fin del año 1594, Madrid, Lorenzo de Ayala, 1598 (Pérez Pastor, Madrid, núm. 572; Thomas, pág. 43). Nótese también Pierre Matthieu, Histoire de France et des choses mémorables, Paris, 1605 (BLGC, vol. 215, pág. 265).

[76] Otro libro yntitulado fran[cis]co de hessa.

[77] Otro libro de cornelio tacito.

Hubo varias traducciones de las obras de Tácito durante los siglos xvi y XviI: Las obras de C. Cornelio Tacito. Traducidas de Latin en Castellano por Emanvel Sveyro, Amberes, Herederos de Pedro Bellero, 1613 (PeetersFontainas, núm. 1251; Beardsley, núm. 143) y Madrid, Viuda de Alonso Martín, 1614 (Salvá, núm. 2792; Pérez Pastor, Madrid, núm. 1306); Los cinco primeros libros de los Annales de Cornelio Tacito... Traducidos de lengua latina en castellana por Antonio de Herrera, Madrid, Juan de la Cuesta, 1615 (Salvá, núm. 2794; Pérez Pastor, Madrid, núm. 1372; Beardsley, núm. 149). Véanse también el núm. 83 abajo y Simón Díaz, $A u$ tores extranjeros, pág. 50.

[78] Otro libro yntitulado corte en aldea de fran[cis]co Rodriguez.

Francisco Rodrigues Lobo, Corte na aldea, e noites de inverno, Lisboa, Pedro Crasbeeck, 1619 (Salvá, núm. 1964; Goldsmith, R165).

[79] Otro libro de genofonte de la empresa de çiro.

Xenofonte, I sette libri della impresa di Ciro minore, trad. de L. Domenichi, Vinegia, G. Giolito, 1547 (Johnson-Scholderer, pág. 738). También hay traducción española de Diego Gracián: Xenofonte, Las obras de Xenophon trasladadas de Griego en Castellano por el Secretario Diego Gracian, diuididas en tres partes, Salamanca, Juan de Junta, 1552 (Salvá, núm. 2799; Thomas, pág. 100). Entre otras cosas, contiene este volumen las historias de Ciro el mayor y el menor. Véase Simón Díaz, Autores extranjeros, página 39.

[80] Otro libro yntitulado medallas.

Seguramente Antonio Agustín, Diálogos de medallas inscriciones y otras antiguedades, Tarragona, Felipe Mey, 1587 (Salvá, núm. 3535; Thomas, pág. 2; Penney, pág. 11 ; Simón Díaz, BLH, IV, núm. 2972; Lastanosa, núm. 92).

[81] Otro libro de las canciones y sonetos del petrarqua.

Francisco Petrarca, Los Sonetos y Canciones del Poeta Francisco Pe- 
trarcha, que traduzia Henrique Garces de Lengua Thoscana en Castellana, Madrid, Guillermo Drouy, 1591 (Salvá, núm. 873 ; Pérez Pastor, Madrid, núm. 366; Thomas, pág. 70). Véase Simón Díaz, Autores extranjeros, página 46.

[82] Otro libro de los trihumphos del petrarca.

Francisco Petrarca, los seis triunfos de toscano sacados en castellano con el comento que sobre ellos se hizo, Logroño, Arnao Guillén de Brocar, 1512 (Salvá, núm. 874; Norton, núm. 419; Thomas, pág. 70). El traductor fue Antonio de Obregón. También hubo traducción de Hernando de Hoces: Medina, 1554 y 1555: Salamanca, 1581. Véase Simón Díaz, Autores extranjeros, pág. 45.

[83] Otro libro de aforismos de cornelio tacito. [fol. $683^{v}$ ]

Probablemente Cornelio Tácito, Aphorismos sacados de la historia de Publio Cornelio Tacito, trad. de Benito Arias Montano, Barcelona, Sebastián Matevat, 1614 (Salvá, núm. 2047 ; Penney, pág. 38 ; Beardsley, número 145). Nótese también CoRnelio Tácito, Tacito español, ilustrado con Aforismos, por Don Baltasar Alamos de Barrientos, Madrid, Luis Sánchez, 1614 (Salvá, núm. 2793; Pérez Pastor, Madrid, núm. 1307 ; Solís, página 111). Véase Simón Díaz, Autores extranjeros, pág. 50.

[84] Otro libro de triumphos de Roma.

Tal vez Onofrio Panvinio, Fasti et triumphi Romae, Venetia, V. Valgrisi, 1558 (Johnson-Scholderer, pág. 488; Mendoza, núm. 22).

[85] Otro libro de la cruz conquistada del bracolin.

Francesco Bracciolini, Della Croce racquistata. Poema heroico, Parigi, Renato Ruelle, 1605 (Rhodes, pág. 142).

[86] Otro libro de correcion de la vida Humana.

[87] Otro de rimas y satiras del ariosto.

Lodovico Ariosto, Rime et satire, Venetia, C. Zanetti, 1571 (STC Italy, I, pág. 92).

[88] Otro libro destatutos de la cofradia de la Resurecion.

Estatutos de la Archicofradia, de la SS. Resurreccion de Christo Nuestro Redentor, de la Nacion Española en Roma, Roma, Esteban Paulino, 1603 (Toda i Güell, núm. 1611). Fue cofradía fundada en Roma en 1579 por Juan de Zúñiga, embajador de España en aquel entonces.

[89] Otro de pohemas al Papa vrbano.

En margen: "no bale nada". Maffeo Barberini, nombrado Papa en 1623, era muy conocido y amado de los españoles en Roma. Pastrana también poseyó dos retratos de Urbano VIII (núms. 35 y 41 del inventario de cua- 
dros). Se conocen varias ediciones de los poemas de Urbano VIII (véase Ramírez de Prado, II, págs. 47, 48, 56 y 58), pero no he podido localizar ninguna edición de poemas dedicados al papa.

[90] Otro libro de patronatos de los marquesses de Cañete.

[91] Otro libro de pohemas al cardenal barberino con las armas de su ex [celenci]a en el pergamino.

El Cardenal Francisco Barberini era sobrino del Papa Urbano VIII, quien le mandó a España en marzo de 1626 como su legado "a latere" ante Felipe IV. Pastrana también poseyó dos retratos de él (núms. 35 y 43 del inventario de cuadros).

[92] Otro libro de vna omilia.

En margen: "no bale nada".

[93] Otro libro de las congregaciones de san benito.

Cf. Antonio de Yepes, Coronica general de la orden de San Benito, 7 tomos, Valladolid, Viuda de Francisco Fernández, 1609-21 (Goldsmith, Y14) y Prudencio de Sandoval, Fundaciones de los monesterios del padre Benito, Madrid, Luis Sánchez, 1601 (Pérez Pastor, Madrid, núm. 718; Penney, pág. 499; Ramírez de Prado, II, pág. 157).

[94] Vn libro de tratado desquadron e[n] ytaliano. 